\title{
Development of a Monitoring System for Maintenance and Repair of High-Tech Equipment
}

\author{
Andrey Korneev ${ }^{1}$, Alexandr Kozlov ${ }^{1}$, Tamara Lavrukhina ${ }^{1,}$, and Andrey Strukov ${ }^{1}$ \\ ${ }^{1}$ Institute of Mechanical Engineering, Lipetsk State Technical University, Lipetsk, 398600, Russia
}

\begin{abstract}
The article presents a system for monitoring high-tech equipment, uses methods of system analysis and decision theory to optimize organizational tasks in the maintenance of high-tech equipment. The possibility of optimizing service channels based on the parameters set by the requirements for performing a certain type of work is considered. The monitoring system of high-tech equipment (MSHTE) is presented in the form of blocks that take into account all types of high-tech equipment, components and assemblies of each of them, technical characteristics, operating parameters, a list of the composition of engineering teams that perform the corresponding maintenance work.
\end{abstract}

\section{Introduction}

The purpose of creating a high-tech equipment (HTE) monitoring system (MSHTE) is to structure the company's permanent assets to equipment units, create specifications for equipment units, develop a maintenance and repair strategy (TMRE), create process maps and collect information in the form of a history of TMRE. The high-tech equipment monitoring system (MSHTE) is designed to automate the monitoring, maintenance and repair of equipment at the enterprise by processing the information contained in specifications, process charts, electronic forms and creating a history of equipment repairs.

As the system has been built taking into account the principle of modular construction and the principle of hierarchy, it fully exhibits the properties of reliability, durability and maintainability, that is, the properties of reliability of an automated system. The system must have the following properties:

- integrity - the properties of the system should depend on the properties of its elements;

- reliability - the ability of the system to perform the tasks assigned to it, while maintaining operational performance over time;

- survivability - the ability to maintain productivity when some individual components fail;

- efficiency - a property that characterizes the degree of its adaptability to assigned tasks;

*Corresponding author: lavrukhina_tv@mail.ru 
- optimality - the system reaches the minimum of the selected performance indicator, in which system response time to user requests is used.

Within the framework of the functional structure of the developing system, the following functional subsystems can be distinguished and the tasks they solve can be defined:

1. Management of technical objects:

- basic records of equipment units;

- specifications of equipment units;

- specification of components and materials.

2. Planning of preventive maintenance and repairs (TMRE):

- strategies;

- technological maps of equipment units;

- maintenance schedules;

- electronic forms.

3. Managing activities on TMRE:

- reports on emergency situations and work on the restoration of objects;

- maintenance of applications and orders for TMRE;

- production capacity planning;

- managing job confirmations of TMRE activities;

- history of the TMRE.

\section{Methodology of Researches}

Due to the fact that monitoring, maintenance and repair are complex tasks, the optimal system structure is a modular structure. Such structures are more reliable and easier to operate. The scheme of the functional structure of the system is shown in Figure 1.

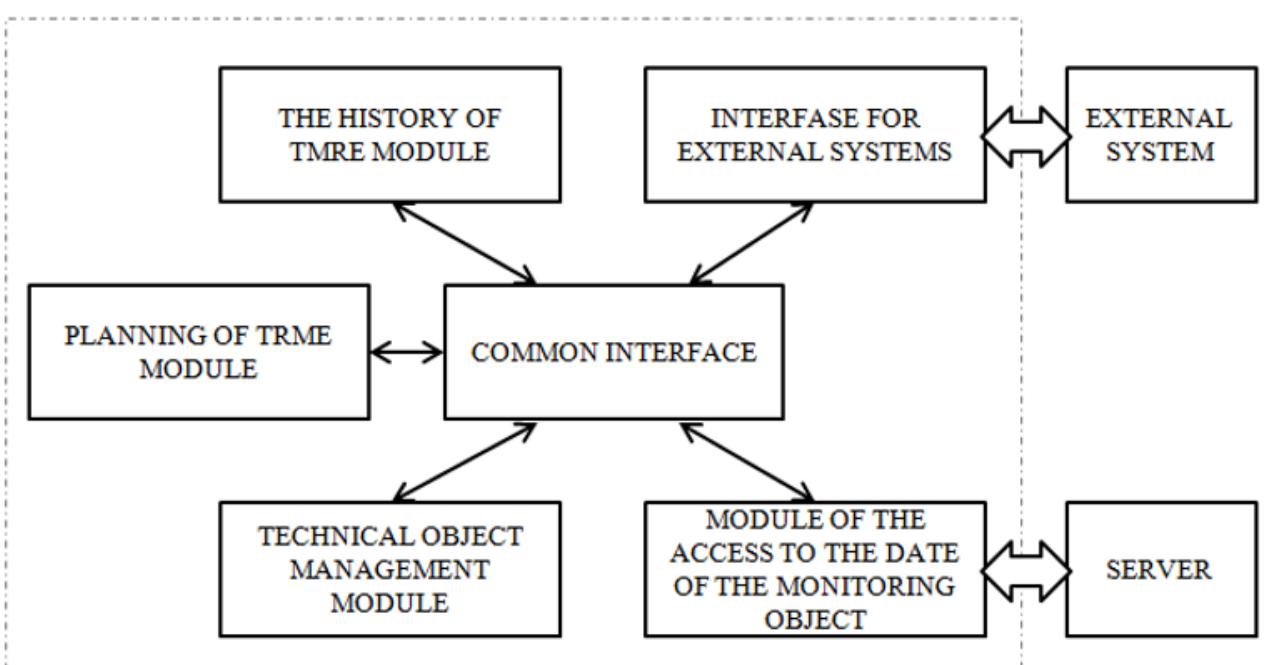

Fig. 1. Functional structure of the monitoring system for high-tech equipment

The following functional modules are allocated in the monitoring system of high-tech equipment:

1. Common interface. Navigates through the system modules, organizes information input, interacts with the database server, and provides data to other system modules.

2. Data access module. Provides interaction of the client functions with the database server to provide the necessary data for the monitoring object. 
3. The module for managing technical objects. Allows the user to work with the equipment available in the enterprise. Includes the ability to create, modify, and delete hardware items, and create and work with equipment specifications.

4. Maintenance and repair planning module. Construction of technological maps of equipment units containing a list of work operations performed during the maintenance and repair of equipment, as well as material and human resources.

5. TMRE history module. Create a history of maintenance and repairs. The equipment maintenance and repair history includes the following data: message history and maintenance history.

6. Interface with external systems. Through this interface, data can be exchanged with other systems.

The system functions are shown in Figure 2.

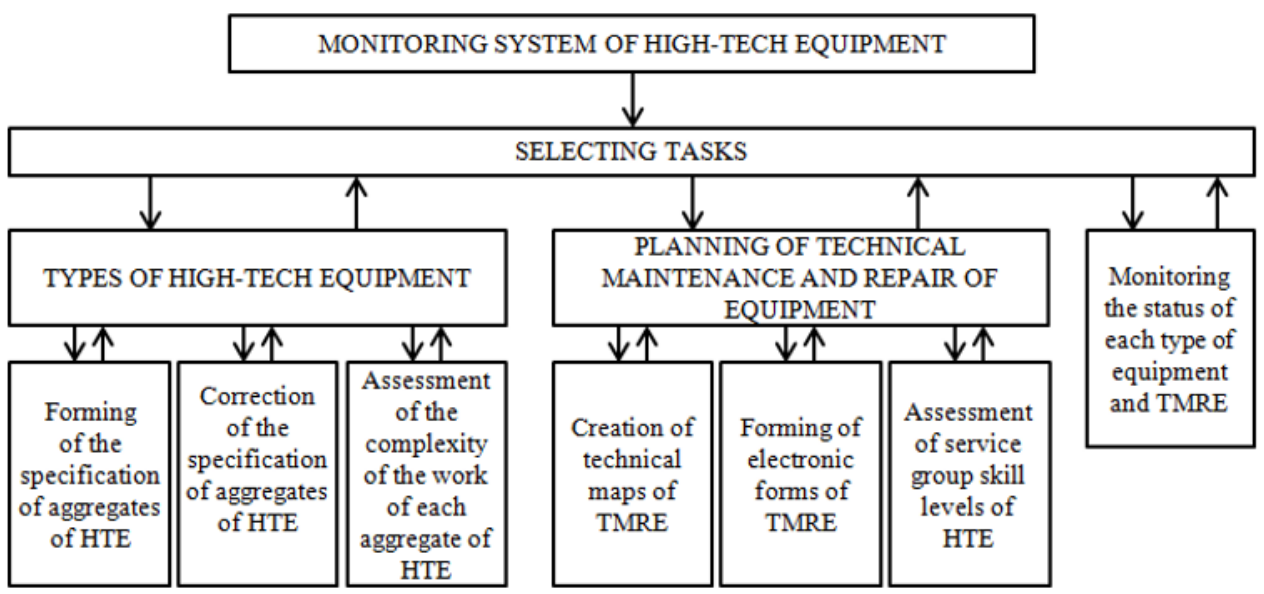

Fig. 2. Monitoring system functions of the high-tech equipment

Optimization of the relationships between the individual levels of the decision-making hierarchy in the automated monitoring system of high-tech equipment that plans equipment maintenance activities, the use of an electronic form, databases, knowledge bases, taking into account the basic factors in the aggregate will minimize the time of technical repair and maintenance of high-tech equipment. This approach will reduce the financial cost of maintenance.

It is necessary to identify the main parameters to implement the tasks of the decisionmaking system for planning the repair of high-tech equipment [1 - 4].

The monitoring system of high-tech equipment (MSHTE) is presented in the form of blocks that take into account all types of high-tech equipment, components and units of each of them, technical characteristics, operating parameters, and a list of engineering teams performing the corresponding maintenance work. The alphabets of the MSHTE are represented as a set of individual symbols containing information about the necessary work on the maintenance of high-tech equipment. Sets of elementary symbols form vectors. The dimension of a vector in the alphabet means the number of its internal components. By means of finite sets of symbols from the given alphabets, the levels of the corresponding blocks are described $[5,6]$.

Alphabets of high-tech equipment, components and aggregates can have different dimensions, and their components are encoded by a certain set of elementary symbols (Table 1): $l=1, \ldots, L$ - type of high-tech equipment, $a_{l}$ - component of alphabets of aggregates of the $l$-th type of high-tech equipment, $a_{l}=1, \ldots, A_{l}$, where $A_{l}$ - number of aggregates of the $l$-th type of high-tech equipment, $n_{l}$-number of high-tech equipment of the 
l-th type: $n_{l}=1, \ldots, N_{l}, N_{l}$ - number of high-tech equipment of the $l$-th type [7-10]. The aggregates of each unit of high-tech equipment are fixed during maintenance and repair.

Table 1. Alphabets of aggregates of high-tech equipment.

\begin{tabular}{|c|c|c|}
\hline $\begin{array}{l}\text { Types of } \\
\text { high-tech } \\
\text { equipment }\end{array}$ & $\begin{array}{l}\text { Numbers of } \\
\text { high-tech } \\
\text { equipment of } \\
\text { each type }\end{array}$ & $\begin{array}{c}\text { Components } \\
\text { of alphabets } \\
\text { of aggregates } \\
\text { of high-tech } \\
\text { equipment of } \\
\text { each type }\end{array}$ \\
\hline $\begin{array}{c}1 \\
\ldots \\
l \\
\cdots \\
L\end{array}$ & $\begin{array}{ccccc}l_{1} & \ldots & n_{l} & \ldots & N_{l} \\
\ldots & \ldots & \ldots \\
1_{l} & \ldots & n_{l} & \ldots & N_{l} \\
\ldots & \ldots & & \ldots \\
l_{L} & \ldots & n_{L} & \ldots & N_{L}\end{array}$ & 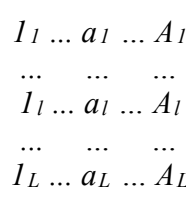 \\
\hline
\end{tabular}

The state of any unit $b_{l a} j_{a_{l}}$ is represented as a component of alphabets that reflects the required type of maintenance or repair ( $l$ - type of high-tech equipment, $a_{l}$ - unit of high-tech equipment, $j_{a_{l}}=1, \ldots, J_{a_{l}}$ - type of maintenance or repair, where $J_{a_{l}}$ - the value of the alphabet of types of maintenance or repair) [11-13].

For example, $b_{l a l} j_{a l}=\{0,1,2,3,4,5\}$, where:

0 - maintenance and repair of the unit is not required,

1 - maintenance, including targeted inspections and inspections,

2 - restoration work,

3 - repair,

4 - replacement of units with a limited resource,

5 - emergency replacement of the unit in case of failure.

As a result, all possible combinations of alphabets of the necessary types of maintenance or repair of the $l$-th type of high-tech equipment are formed:

$$
\begin{aligned}
& \zeta_{\beta_{l}}=\left\{b_{l 11}, \ldots, b_{l 1 J_{1}}\right\} \times \ldots \times\left\{b_{l a_{l} 1}, \ldots, b_{l a_{l}} J_{a_{l}}\right\} \times \ldots \times\left\{b_{l A_{l} 1}, \ldots, b_{\left.l A_{l} J_{A_{l}}\right\}}\right\} \\
& =\left\{\begin{array}{c}
A_{l} \\
\left.\zeta_{\beta_{l}}, \beta_{l}=1, \ldots, B_{l} ; B_{l}=\prod_{i=1} J_{i}\right\}
\end{array}\right.
\end{aligned}
$$

The database of the high-tech equipment monitoring system (MSHTE) contains complete information about the state of the units of each type of equipment $\Xi=\left[\xi_{1}, \ldots, \xi_{l}, \ldots, \xi_{L}\right]$, which is used when forming service requests.

\section{Research Results}

When developing a monitoring system, a hierarchical structure of indicators of high-tech equipment is formed (Fig. 3). 


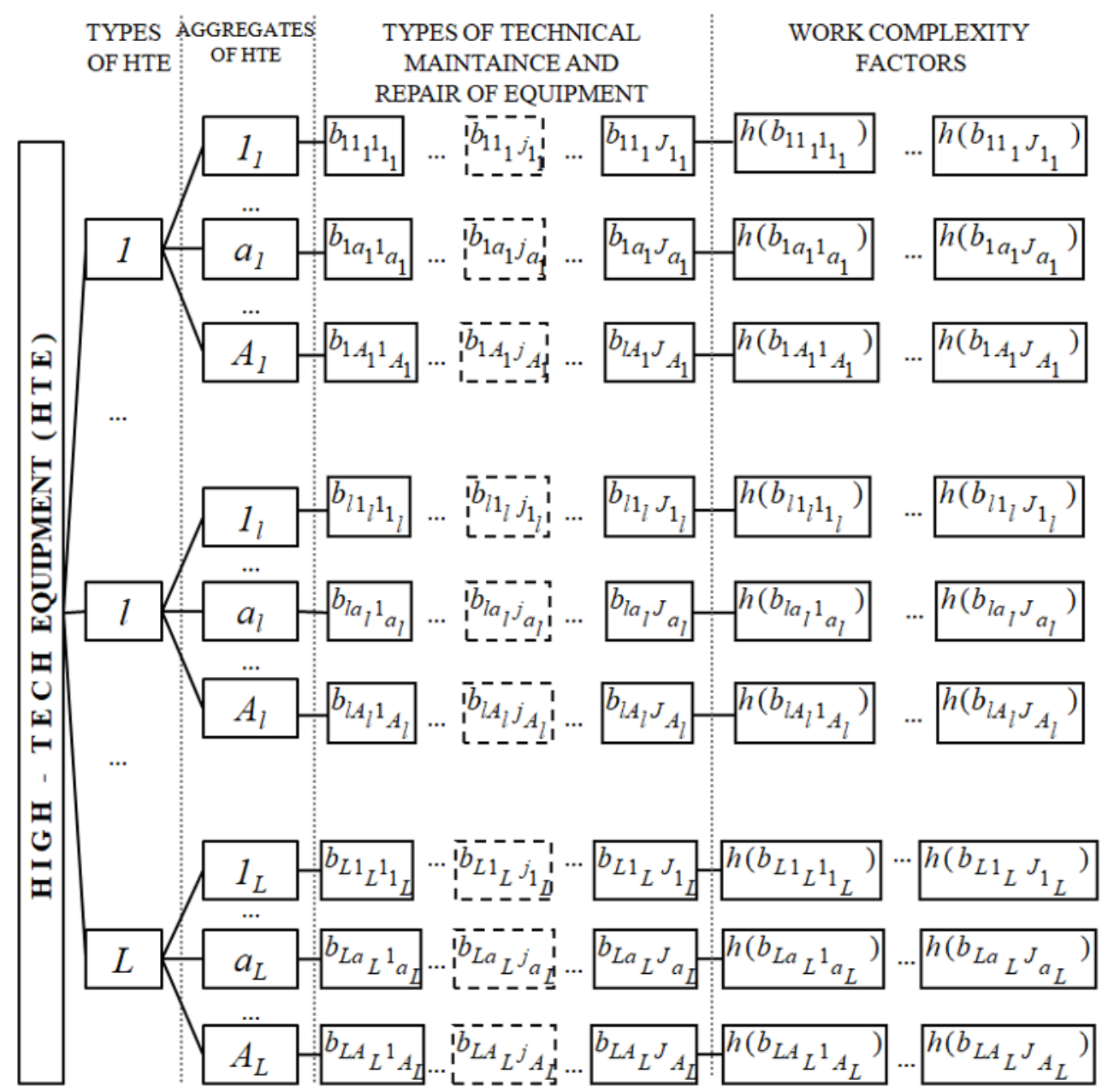

Fig. 3. General hierarchical structure of the indicators of the monitoring object

Table 2. Indicators of the complexity of the work of high-tech equipment.

\begin{tabular}{|c|c|c|c|c|}
\hline \multicolumn{5}{|c|}{ Type of high-tech equipment } \\
\hline 1 & $\ldots$ & $l$ & $\ldots$ & $L$ \\
\hline \multicolumn{5}{|c|}{ Aggregates (units) of each type of high-tech equipment } \\
\hline$l_{1} \ldots a_{1} \ldots A_{1}$ & $\ldots$ & $l_{l} \ldots a_{l} \ldots A_{l}$ & $\ldots$ & $1_{L} \ldots a_{L} \ldots A_{L}$ \\
\hline \multicolumn{5}{|c|}{ Generalized coefficients of work complexity } \\
\hline$H_{1_{1}} \ldots H_{a_{1}} \ldots H_{A_{1}}$ & $\ldots$ & $H_{1} \ldots H_{a l} \ldots H_{A l}$ & $\ldots$ & $H_{1}{ }_{L} \ldots H_{a_{L}} \ldots H_{A_{L}}$ \\
\hline \multicolumn{5}{|c|}{ Work complexity factors } \\
\hline $\begin{array}{c}h\left(b_{11_{1} 1_{1}}\right) \ldots h\left(b_{1 a_{1} 1_{a_{1}}}\right) \ldots h\left(b_{1 A_{1} 1_{A_{1}}}\right) \\
\ldots \\
h\left(b_{11_{1} j_{1_{1}}}\right) \ldots h\left(b_{1 a_{1} j_{a_{1}}}\right) \ldots h\left(b_{1 A_{1} j_{A_{1}}}\right) \\
\ldots \\
h\left(b_{11_{1} J_{1_{1}}}\right) \ldots h\left(b_{1 a_{1} J_{a_{1}}}\right) \ldots h\left(b_{1 A_{1} J_{A_{1}}}\right)\end{array}$ & $\cdots$ & $\begin{array}{c}h\left(b_{l l_{l} 1_{l}}\right) \ldots h\left(b_{l a_{l} 1_{a_{l}}}\right) \ldots h\left(b_{l A_{l} 1_{A_{l}}}\right) \\
\ldots \\
h\left(b_{l 1_{l} j_{1_{l}}}\right) \ldots h\left(b_{l a_{l} j_{a_{l}}}\right) \ldots h\left(b_{l A_{l} j_{A_{l}}}\right) \\
\ldots \\
h\left(b_{l 1_{l} J_{1_{l}}}\right) \ldots h\left(b_{l a_{l} J_{a_{l}}}\right) \ldots h\left(b_{l A_{l} J_{A_{l}}}\right)\end{array}$ & $\cdots$ & $\begin{array}{c}h\left(b_{L 1_{L} 1_{L}}\right) \ldots h\left(b_{L a_{L} 1_{a_{L}}}\right) \ldots h\left(b_{L A_{L} 1_{A_{L}}}\right) \\
\ldots \\
h\left(b_{L 1_{L} j_{1_{L}}}\right) \ldots h\left(b_{L a_{L} j_{a_{L}}}\right) \ldots h\left(b_{L A_{L} j_{A_{L}}}\right) \\
\ldots \\
h\left(b_{L 1_{L} J_{1_{L}}}\right) \ldots h\left(b_{L a_{L} J_{a_{L}}}\right) \ldots h\left(b_{L A_{L} J_{A_{L}}}\right)\end{array}$ \\
\hline
\end{tabular}


The main types of equipment are determined $l=1, \ldots, L$ ( $L$ is the number of the investigated types). The number of aggregates $A_{l}$ is determined for each type of high-tech equipment. The condition of any unit $b_{l a} j_{a_{l}}$ allows you to choose the necessary type of maintenance or repair. The structure of indicators of high-tech equipment includes coefficients of work complexity $h\left(b_{l a} j_{a_{l}}\right)$ (Table 2$)$.

Generalized coefficients of the complexity of the work of each unit $a_{l}$

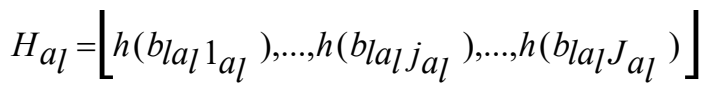

are used when the priorities of work and formation of optimal order of actions are determined. The monitoring system of high-tech equipment (MSHTE) takes into account the parameters of the equipment received for maintenance and based on data of service groups and work priorities and it forms the optimal order of actions (Figure 4).

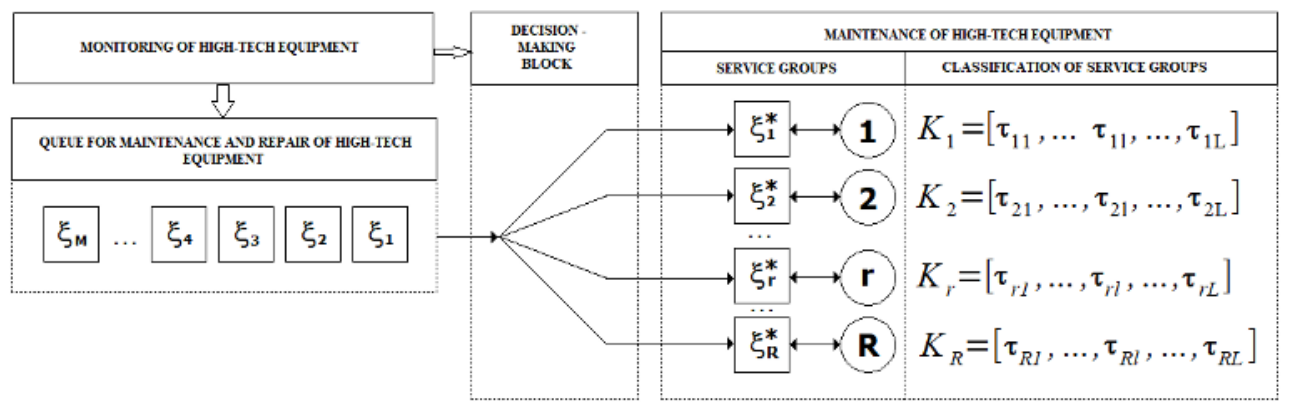

Fig. 4. Formation of the optimal order of maintenance of high-tech equipment.

\section{Conclusion}

An important goal is to improve the maintenance process of high-tech equipment, minimize the time spent on maintenance and improve the quality of repairs. The article presents a system for monitoring high-tech equipment uses methods of system analysis and decision theory to optimize organizational tasks in the maintenance of high-tech equipment. The possibility of optimizing service channels based on the parameters set by the requirements for performing a certain type of work is considered. The monitoring system of high-tech equipment (MSHTE) is presented in the form of blocks that take into account all types of high-tech equipment, components and units of each of them, technical characteristics, operating parameters, a list of the composition of engineering teams that perform the corresponding maintenance work.

High productivity of maintenance services in the conditions of various factors of uncertain factors (accidents, equipment failure and emergency situations) is, of course, the most important condition for ensuring the safety of operation. To reduce the number of uncertain factors and increase the reliability of high-tech equipment is the main goal of implementing a monitoring system for high-tech equipment, which, using appropriate techniques, will allow you to coordinate the repair plan for each engineering service: to eliminate downtime, to minimize inconsistency between related services for the repair of individual components and aggregates. 


\section{References}

1. A. M. Korneev., S. L. Blyumin, A. M. Nagi, Modelling Processes of Functioning of Complex Multistage Production System, International Journal of Advanced Biotechnology and Research, Vol. 9 (1), pp. 1332- 1337, (2018)

2. A. Kozlov, E. Kiryuschenko, A. Kirichek, Technological system self-tuning when milling MATEC Web of Conferences 129 (ICMTMTE 2017), 01033 (2017)

3. A. M. Kozlov, Kh. M. Al-jonid, A. A. Kozlov, Sh D Antar, Product quality management based on CNC machine fault prognostics and diagnosis, MEACS 2017 IOP Publishing, IOP Conf. Series: Materials Science and Engineering 327, 022067, (2018)

4. A.M. Korneev, M.V. Salfetnikov, Y.A. Glazkova, T.V. Lavrukhina, L.S. Abdullakh, Emergency risks situations computation for intellectual support in administration of decisions, Journal of Computational and Theoretical Nanoscience, № 1, pp. 105-108, (2019)

5. S. N. Grigoriev, A. G. Andreev, G. M. Martinov, Prospects for the development of cross-platform computer systems for numerical software control of high-tech equipment, Automation in Industry, No. 5, pp. 3-8, (2011)

6. Yu. I. Savinov, Debugging and adjustment of CNC machines using methods of nonselective diagnostics, Tools, technologies, and equipment, 10, pp. 50-52, (2008)

7. F. Camci, Autonomous, Process Monitoring, Diagnostics, and Prognostics Using Support Vector Machines and Hidden Markov Models (Ph.D. Dissertation, Industrial and Manufacturing Engineering, Wayne State University, Detroit, MI, USA, 2005)

8. A.M. Shmyrin, A.G. Yartsev, Damping procedure for mixed control with varia-ble coefficients of the neighborhood model, International Journal of Engineering and Technology(UAE), 7(3), pp. 21-23, (2018)

9. A.G. Yartsev, A.M. Shmyrin, E.S. Podvalny, Options for Identification and Mixed Control of Neighborhood Systems, Proceedings - 2019 1st International Conference on Control Systems, Mathematical Modelling, Automation and Energy Efficiency, SUMMA 2019, pp. 56-59, 8947576, (2019)

10. P. Saraev, S. Blyumin, A. Galkin, A. Sysoev, Mathematical Remodeling Con-cept in Simulation of Complicated Variable Structure Transportation Systems, Transportation Research Procedia, 45, pp. 475-482, (2020)

11. A. Pogodaev, A. Galkin, P. Saraev, A. Miroshnikov, The Development of In-terval Data Type for Analytical Information Processing, Studies in Fuzziness and Soft Computing, 393, pp. 509-520, (2021)

12. N. Mishachev, A. Shmyrin, I. Suprunov, Simulation of sequential processing of a moving extended object, International Transaction Journal of Engineering, Management and Applied Sciences and Technologies, Vol. 11, № 7, P. 11A07T, (2020)

13. N. Mishachev, A. Shmyrin, On realization of limit polygons in sequential projection method, International Transaction Journal of Engineering, Management and Applied Sciences and Technologies, Vol. 10, № 15, p. 10A15GM, (2019) 